\title{
Estágio Supervisionado na Formação de Professores a partir de trabalhos apresentados em edições do ENPEC
}

\author{
Supervised Internship in Teacher Education based on works presented in \\ editions of ENPEC

\section{Pasantía Supervisada en Formación Docente basada en trabajos presentados en ediciones ENPEC}

\begin{abstract}
Jolúcia Santos de Jesus; (josjesus@uesc.br)
Universidade Estadual de Santa Cruz, UESC.

Kaique Nascimento Martins; (knmartins@uesc.br)

Universidade Estadual de Santa Cruz, UESC.

Andrei Steveen Moreno-Rodríguez; (asmrodriguez@uesc.br)

Universidade Estadual de Santa Cruz, UESC.

Elisa Prestes Massena; (epmassena@uesb.br)

Universidade Estadual de Santa Cruz, UESC.

Resumo: O Estágio Supervisionado faz parte da formação docente e visa oportunizar ao licenciando uma aproximação com a realidade escolar, permitindo-lhe conhecer e refletir sobre seu ambiente profissional. Dessa forma, este trabalho visa investigar quais propósitos são identificados nas pesquisas do Encontro Nacional de Pesquisa em Ensino de Ciências (ENPEC) que versam sobre o estágio supervisionado, após a publicação das Resoluções CNE/CP 02/2015 e 02/2019. Intenciona-se compreender o que vem sendo publicado no referido evento sobre estágio supervisionado. Utilizou-se a pesquisa bibliográfica para mapear as produções em um período delimitado de quatro anos (2016 a 2019). Os dados foram analisados tomando por base a análise de conteúdo. Como resultados, foram encontrados 37 trabalhos que versavam sobre estágio supervisionado, que foram agrupados em cinco categorias, a saber: Estágio: teoria e prática na ação docente; Estágio como espaço para construção de saberes e da identidade docente; Estágio como espaço para pesquisas; Estágio nas concepções de professores formadores, supervisores, pós-graduandos e licenciandos; Estágio em espaços não formais. Concluiu-se que as publicações do evento de Ensino de Ciências aqui analisadas estão voltadas para pesquisas sobre teoria e prática na ação docente, saberes e identidade docente, a visão envolvida no processo do estágio e estágio com pesquisa.
\end{abstract}

Palavras-chave: Estágio Supervisionado; Formação de professores; Ensino de Ciências.

Recebido em: 10/01/2021

Aceite em: 01/10/2021 


\begin{abstract}
The Supervised Internship is part of teacher training and aims to provide the licentiate with an approach to the school reality, allowing them to know and reflect on their professional environment. Thus, this work aims to investigate which purposes are identified in the surveys of the National Meeting of Research in Science Education (ENPEC) that deal with supervised internship, after the publication of CNE/CP Resolutions $02 / 2015$ and 02/2019. It is intended to understand what has been published in that event about supervised internship. Bibliographic research was used to map the productions in a limited period of four years (2016 to 2019). Data were analyzed based on content analysis. As a result, 37 works were found that dealt with supervised internship, which were grouped into five categories, namely: Internship: theory and practice in the teaching action; Internship as a space for building knowledge and teaching identity; Internship as a space for research; Internship in the conceptions of teacher trainers, supervisors, graduate students, and Undergraduates; Internship in nonformal spaces. It was concluded that the publications of the Science Teaching event analyzed here are focused on research on theory and practice in teaching action, wisdom and teaching identity, the vision involved in the internship and internship process with research.
\end{abstract}

Keywords: Supervised Internship; Teacher Training; Science Teaching.

Resumen: La Práctica Supervisada forma parte de la formación del profesorado y tiene como objetivo proporcionar al licenciado un acercamiento a la realidad escolar, permitiéndole conocer y reflexionar sobre su entorno profesional. Así, este trabajo tiene como objetivo indagar qué fines se identifican en las encuestas del Encuentro Nacional de Investigación en Docencia Científica (ENPEC) que abordan el internado supervisado, tras la publicación de las Resoluciones CNE / CP 02/2015 y 02/2019. Se pretende comprender lo que se ha publicado en ese evento sobre prácticas supervisadas. Se utilizó la investigación bibliográfica para mapear las producciones en un período limitado de cuatro años (2016 a 2019). Los datos se analizaron con base en el análisis de contenido. Como resultado, se encontraron 37 trabajos que versaron sobre prácticas supervisadas, que se agruparon en cinco categorías, a saber: Prácticas: teoría y práctica en la acción docente; La pasantía como espacio de construcción de conocimiento e identidad docente; La pasantía como espacio de investigación; Pasantía en las concepciones de formadores de docentes, supervisores, estudiantes de posgrado y pregrado; Prácticas en espacios no formales. Se concluyó que las publicaciones del evento de Enseñanza de las Ciencias aquí analizadas se centran en la investigación sobre la teoría y la práctica en la acción docente, la sabiduría y la identidad docente, la visión involucrada en el proceso de pasantía y pasantía con la investigación.

Palabras-clave: Pasantía Supervisada; Formación de Profesores; Enseñanza de las Ciencias.

Recebido em: 10/01/2021

Aceite em: $01 / 10 / 2021$ 


\section{INTRODUÇÃO}

O Estágio Supervisionado faz parte da matriz curricular obrigatória da maioria dos cursos de licenciatura e é considerado uma atividade instrumentalizadora da práxis docente, um espaço para fundamentação, diálogo e intervenção da realidade. Pimenta e Lima (2011) afirmam que o estágio deve propiciar o conhecimento, a investigação, a problematização, o questionamento de um dado objeto, bem como a reflexão e análise detalhada do trabalho docente, para que ocorram as transformações necessárias no espaço escolar.

$\mathrm{Na}$ formação dos professores de Ciências, o Estágio Supervisionado tem sido o foco de estudos nos últimos anos, ocupando espaço próprio de debate em eventos científicos da área, a exemplo do Encontro Nacional de Pesquisa em Ensino de Ciências (ENPEC), que é um encontro bienal, promovido pela Associação Brasileira de Pesquisa em Educação em Ciências (ABRAPEC) ${ }^{1}$.

Nesse evento, há uma diversidade de publicações $^{2}$, dentre as quais podemos citar o trabalho de Lopéz e Nardi (2017), o qual delineia um panorama geral do que vem sendo publicado em eventos nacionais na área de Física sobre estágio supervisionado, organizando os trabalhos em três categorias: sujeitos envolvidos; estágio e pesquisa; e o processo do estágio supervisionado, ratificando que essa etapa supera a simples aplicação de metodologias e técnicas de ensino.

Além dos eventos da área, há discussões publicadas em periódicos diversos, como a pesquisa de Assai, Broietti e Arruda (2018), que apresenta um mapeamento realizado em periódicos da área de Ensino de Ciências sobre estágios supervisionados, trazendo oito categorias que expressam os principais aspectos encontrados nos trabalhos analisados, como sugestões de estratégias ou discussão teórica. Os autores constataram que o estágio se desenvolveu como campo de pesquisa na década de 2008-2018 em decorrência das modificações propostas pelas Diretrizes Nacionais Curriculares para a

\footnotetext{
${ }^{1}$ Disponível em: http://abrapecnet.org.br/wordpress/pt/2020/04/

${ }^{2}$ Linheira, Neto e Jófili (2019) vêm relatando a percepção dos licenciandos sobre sua participação no estágio supervisionado em ciências, trazendo uma reflexão sobre a prática educativa, enxergando o estágio como uma forma de superar a perspectiva tradicional, mesmo que durante o estágio existam algumas diferenças entre o comportamento pretendido e aquele efetivado nas aulas.
}

Recebido em: 10/01/2021

Aceite em: $01 / 10 / 2021$ 
Formação de Professores (CNE/CP 09/2001), as quais trouxeram mudanças para os cursos de licenciatura e organização dos estágios. É importante ressaltar que mais da metade dos artigos foram publicados após o ano de 2015, em decorrência da resolução CNE/CP 02/2015 (BRASIL, 2015), que altera a organização da estrutura curricular dos cursos de licenciatura. As discussões predominaram nos cursos de Biologia, seguido pelos cursos de Física, Química e Ciências, respectivamente. Em conclusão, apontaram falta de um entendimento do mesmo com espaço coletivo de formação.

Alguns autores vêm apresentando críticas a esta etapa de formação. Pimenta e Lima (2011) explicam que o estágio supervisionado tem sido questionado por apresentar limitações no percurso formativo, a exemplo da dissociação entre teoria e prática. Ghedin, Oliveira e Almeida (2015) apontam a necessidade de articulação do mesmo com a pesquisa como condição para construção da autonomia do professor. Dessa forma, é necessário abrir discussão para o estágio supervisionado na formação de professores, pois essa etapa deve ser permeada pela problematização e pela reflexão do trabalho docente.

O presente trabalho visa investigar quais propósitos são identificados nas pesquisas do Encontro Nacional de Pesquisa em Ensino de Ciências (ENPEC) que versam sobre estágio supervisionado após a publicação das Resoluções CNE/CP 02/2015 e 02/2019. Intenciona-se compreender o que vem sendo publicado no ENPEC sobre estágio supervisionado, em que serão mapeadas as produções em um período delimitado de quatro anos (2016 a 2019). Ressalta-se que este trabalho é oriundo de uma pesquisa de mestrado em andamento que busca compreender o processo de formação do licenciando no Estágio Supervisionado.

\section{ESTÁGIO SUPERVISIONADO}

A formação inicial de professores tem sido objeto de debates constantes, pois um dos desafios da contemporaneidade é a melhoria da formação inicial e do sistema educacional brasileiro (VEIGA; VIANA, 2012; DINIZ-PEREIRA, 2014; NÓVOA, 2017; SOUSA; SILVA; BEDIN, 2020).

Recebido em: 10/01/2021

Aceite em: $01 / 10 / 2021$ 
A formação inicial de professores vem sendo debatida desde a época de Comenius, no século XVII, e passou a ser discutida de uma forma mais sistemática a partir da década de 1980, período marcado por intensas análises e questionamentos sobre a profissionalização docente, instigado pela mobilização e organização dos educadores em associações sindicais (HORIKAWA, 2015).

A partir da década de 1990, houve um período de reformas na área educacional, e a Lei de Diretrizes e Bases da Educação Nacional, LDBN 9.394/96 (BRASIL, 1996), trouxe mudanças, determinando que a formação de professores para o exercício na educação básica aconteça em nível superior. Nesse contexto de mudanças, houve a necessidade de se pensar a formação inicial e as práticas no Estágio Supervisionado.

Regido pela Lei 11.788/2008 e Lei de Diretrizes e Bases da Educação Nacional (LDB n 9394/96), o Estágio Supervisionado é uma etapa necessária aos cursos de formação de professores e uma exigência da lei, com o objetivo de o estagiário entrar em contato com situações reais de trabalho, permitindo ao estudante analisar e conhecer seu ambiente profissional.

Por isso, o Estágio Supervisionado precisa ser uma etapa da formação inicial em que o licenciando vivencie as percepções associadas ao tornar-se um professor, conhecendo os desafios e dificuldades essenciais a este processo (GHEDIN; OLIVEIRA; ALMEIDA, 2015; PIMENTA; LIMA, 2011; CARVALHO, 2012).

A Resolução CNE/CP No 2, de 20 de dezembro 2019 (BRASIL, 2019) possibilitou espaços de discussão acerca da dimensão prática e crítica na constituição docente e instituiu a Base Nacional Comum para a Formação Inicial de Professores da Educação Básica (BNC-Formação). A referida resolução determina a carga horária para a Prática dos Componentes Curriculares e dos Estágios:

[...] a) 400 (quatrocentas) horas para o estágio supervisionado, em situação real de trabalho em escola, segundo o Projeto Pedagógico do Curso (PPC) da instituição formadora; e

b) 400 (quatrocentas) horas para a prática dos componentes curriculares dos Grupos I e II, distribuídas ao longo do curso, desde o seu início, segundo o PPC da instituição formadora. (BRASIL, 2019).

Recebido em: 10/01/2021

Aceite em: $01 / 10 / 2021$ 
A Resolução CNE/CP n. 2/2019 apresenta uma carga horária para o Grupo III, com ênfase na prática, dividida em 400 horas de estágio supervisionado e 400 horas de práticas como componentes curriculares. Importante registrar que a referida Resolução trata exclusivamente da formação inicial de professores e da BNC-Formação, ficando a formação continuada esquecida, não sendo referenciada, conforme constava na antiga Resolução CNE/CP n. 2/2015, que instituía as Diretrizes Curriculares Nacionais para a Formação Inicial e Continuada de Profissionais do Magistério.

Assim, surgiu um vasto debate nos setores da sociedade, discutindo-se possibilidades para a formação inicial e continuada (JANERINE; QUADROS, 2018). Os autores analisaram uma experiência de um grupo de professores em formação, ao serem inseridos na docência e terem suas aulas avaliadas coletiva e individualmente. $\mathrm{O}$ estudo apontou a necessidade da reflexão na formação docente, para que o licenciando possa construir uma ideia mais consistente sobre o ser professor, ser estudante e do papel do conteúdo em sala de aula. Assim, o Estágio supervisionado e todo o processo formativo devem trazer reflexões sobre a prática docente.

O estágio se institui como um momento formativo em que o futuro professor constrói competências, conhecimentos e habilidades para a sua atuação profissional. Pimenta e Lima (2011) afirmam que a finalidade do estágio supervisionado é contribuir para a formação docente e é eixo articulador do currículo em diálogo constante entre formação inicial e continuada. As autoras justificam que essa etapa do processo de formação inicial deve favorecer a avaliação de novas formas de pensar os conteúdos, a escola e seus currículos, etapa em que o futuro professor adquirirá experiências que nortearão a construção do que é ser professor.

Ghedin, Oliveira e Almeida (2015) endossam a análise anterior, afirmando que a formação de professores deve ser baseada na pesquisa como um elemento chave de construção de conhecimentos, como possibilidade de superação de modelos em que o professor seja um mero reprodutor das teorias. O estágio com pesquisa é uma possibilidade de o professor elaborar os próprios conhecimentos a partir de um saber já consolidado por meio da reflexão sobre a prática. Os autores compreendem a pesquisa como uma possibilidade de o professor tornar-se um sujeito que, além de produzir seu

Recebido em: 10/01/2021

Aceite em: $01 / 10 / 2021$ 
próprio conhecimento, torna-se um construtor de seu próprio modo de ser e fazer, por meio da reunião de dados do objeto do conhecimento que nos propomos a conhecer.

Carvalho (2012) amplia a discussão levantando a necessidade de uma maior interação do licenciando com a unidade escolar, para obter dados significativos que possibilitem uma reflexão crítica do trabalho a ser desenvolvido como professor. Dessa forma, o estágio supervisionado é o momento de fortalecer a teoria e a prática, na qual o futuro docente visualize a prática como ação e reflexão crítica. A ação faz referência aos sujeitos, seu modo de pensar e agir, seus valores, seu modo de se relacionar e de ver o outro no mundo.

Günzel (2019) apresenta um relato de experiência que mostra o estágio como uma possibilidade de superar os próprios medos da regência e como uma possibilidade de aprender, na prática, conteúdos de área que sentia dificuldade em aprender durante as aulas teóricas. Ela relata que aprendeu muito mais sobre Física ao lecionar sobre conceitos científicos do que propriamente sendo aluna. Assim, os cursos de formação de professores precisam proporcionar oportunidades didáticas em que os futuros docentes possam aplicar os conhecimentos que aprenderam, a fim de mobilizar diferentes saberes na prática pedagógica.

\section{PERCURSO METODOLÓGICO}

Para a realização deste trabalho, utilizou-se a pesquisa bibliográfica, com o intuito de mapear as produções em um período delimitado de quatro anos (2016 a 2019), isso pela necessidade de apresentar quais têm sido as últimas publicações sobre essa temática e para compreender o movimento em torno da implementação das Resoluções CNE/CP 02/2015 de 01 de julho de 2015 (BRASIL, 2015) e CNE/CP No 2 de 20 de dezembro 2019 (BRASIL, 2019), que determinam as Diretrizes Curriculares Nacionais para a formação de professores, estabelecendo a carga horária para os estágios supervisionados.

Foram investigados os artigos do ENPEC por se tratar de um evento nacional representativo da área de Ensino de Ciências. Consideramos que é um evento relevante, pois reúne pesquisas na área de Ensino e abrange as três áreas do Ensino de Ciências,

Recebido em: 10/01/2021

Aceite em: $01 / 10 / 2021$ 
respectivamente: Química, Física e Biologia. Como o ENPEC é um evento bienal, foram investigadas as edições de 2017 e 2019.

Para construir este panorama sobre o Estágio Supervisionado, foi realizada uma revisão levando-se em consideração trabalhos publicados no ENPEC, disponibilizados eletronicamente e que podem ser encontrados nos $\operatorname{sites}^{3}$ do evento.

A pesquisa inicial foi efetuada pelo link de busca na página inicial do evento, na qual foi inserida a palavra-chave "Estágio". Para confirmar o quantitativo, realizamos uma segunda busca por meio da palavra "Estágio Supervisionado", com a finalidade de investigar se os artigos selecionados estavam consonantes com o objeto desta pesquisa. Para tanto, realizou-se, inicialmente, a leitura dos títulos e resumos, com o intuito de localizar os objetivos dos trabalhos. No total, foi identificado um quantitativo de 37 publicações.

Todos os trabalhos versavam sobre o estágio supervisionado no ensino de Ciências ou formação de professores. Alguns trabalhos discutiam a temática em maior ou menor grau, mas todos foram considerados, não havendo, portanto, critério de exclusão. Os instrumentos para obter as informações foram os anais dos eventos divulgados.

Com o objetivo de compreender a discussão feita por pesquisadores/educadores sobre a temática do estágio supervisionado, utilizou-se dos procedimentos da Análise de Conteúdo proposto por Bardin (2011), descritos a seguir.

a) A pré-análise envolveu a etapa de organização do material e codificação dos 37 trabalhos que compõem esta pesquisa, identificando o ano de publicação e a ordem crescente dos trabalhos.

b) A etapa de exploração do material compreendeu o estudo aprofundado do corpus. Nessa etapa, elaboramos uma planilha com alguns dados: título, ano de publicação, autores e área. Posteriormente, partimos para a unidade de registro, concentrando nos objetivos de cada trabalho. Para essa etapa, realizamos a interpretação dos objetivos de forma a agrupá-los conforme as características comuns (categorização).

${ }^{3}$ Ano de 2017, disponível em: http://www.abrapecnet.org.br/enpec/xi-enpec/anais/trabalhos.htm. Ano de 2019, disponível em: http://abrapecnet.org.br/enpec/xii-enpec/anais/trabalhos.htm

Recebido em: 10/01/2021

Aceite em: $01 / 10 / 2021$ 
Ainda selecionamos palavras chaves, para classificar cada publicação dentro de uma determinada categoria. Esse processo resultou em 5 (cinco) categorias a posteriori, discutidas e exploradas na próxima seção.

c) O tratamento dos resultados obtidos compreendeu a interpretação das categorias feitas por meio da inferência, embasados no referencial teórico adotado e na intuição dos pesquisadores. Os trabalhos analisados estão disponíveis no Quadro 2, na parte final deste texto, na seção de anexos.

\section{ESTÁGIO SUPERVISIONADO: O QUE VEM SENDO}

\section{PUBLICADO A PARTIR DE TRABALHOS APRESENTADOS EM EDIÇÕES DO ENPEC}

Sobre o mapeamento dos artigos em relação ao Estágio Supervisionado na área de ensino de Ciências, encontramos 37 artigos, dos quais 15 são referentes ao ano de 2017 e 22 artigos ao ano de 2019, que foram agrupados conforme quadro 1 :

\begin{tabular}{|l|c|c|l|}
\hline \multicolumn{2}{|c|}{ Quadro 1 - Categorias de análises. } \\
\hline $\begin{array}{l}\text { Categorias } \\
\text { evista Insianare }\end{array}$ & $\begin{array}{l}\mathbf{N}^{0} \text { de trabalhos } \\
\text { (2017) }\end{array}$ & $\begin{array}{l}\mathbf{N}^{\mathbf{0}} \\
\text { trabalhos }\end{array}$ & de \\
(2019) & \\
\hline $\begin{array}{l}\text { 1-Estágio: teoria e prática na } \\
\text { ação docente. }\end{array}$ & --- & 03 & Química/Física \\
\hline $\begin{array}{l}\text { 2-Estágio como espaço para } \\
\text { construção de saberes e da } \\
\text { identidade docente. }\end{array}$ & 02 & 03 & $\begin{array}{l}\text { Química/Física/B } \\
\text { iologia }\end{array}$ \\
\hline $\begin{array}{l}\text { 3-Estágio como espaço para } \\
\text { pesquisas }\end{array}$ & 05 & 11 & $\begin{array}{l}\text { Química/Física/B } \\
\text { iologia }\end{array}$ \\
\hline $\begin{array}{l}\text { 4-Estágio nas concepções de } \\
\text { professores formadores, } \\
\text { supervisores, pós-graduandos, }\end{array}$ & 05 & 05 & $\begin{array}{l}\text { Química/Física/B } \\
\text { iologia/Matemáti } \\
\text { ca/Ciências }\end{array}$ \\
\hline
\end{tabular}

Recebido em: 10/01/2021

Aceite em: 01/10/2021 


\begin{tabular}{|l|c|c|l|}
\hline e Licenciandos & & & \\
\hline $\begin{array}{l}\text { 5-Estágio em espaços não } \\
\text { formais }\end{array}$ & 03 & -- & Biologia/Física \\
\hline TOTAL: & 15 & 22 & -- \\
\hline
\end{tabular}

Fonte: Autores, 2021.

Tendo como base os trabalhos identificados sobre Estágios Supervisionados nos anais do evento, serão apresentados, de agora em diante, apenas alguns trabalhos, os quais estão identificados por códigos e referenciados nos anexos desta pesquisa. Optouse pela exemplificação de apenas alguns, devido ao número extenso de trabalhos localizados.

\subsection{Estágios: Teoria e prática na ação docente}

Essa categoria compreende os trabalhos que vêm discutindo a relação teoria e prática na ação docente. As palavras chaves utilizadas como núcleo da categoria foram: relação teórico-prática; Prática Como Componente Curricular; Prática de Ensino. Alguns trabalhos relatam a articulação teórico-prática na formação de professores, a prática no Projeto Pedagógico de Curso da Licenciatura em Química e as escritas dos licenciando acerca do conceito de teoria e prática na ação docente. Como exemplo, o trabalho identificado abaixo objetivou:

[...] compreender os entendimentos dos licenciandos, que estavam cursando o primeiro componente de Estágio, acerca da teoria e da prática na ação docente (TP03, p.2).

Esse trabalho apresenta uma análise da escrita de 15 licenciandos em Química sobre teoria e prática na ação docente e mostra que a teoria é percebida, pelos mesmos, como conhecimentos que não se associam com a prática, ou seja, os licenciandos exibem poucas compreensões, visões limitantes e reducionistas dessa articulação (dissociação entre teoria e prática).

Recebido em: 10/01/2021

Aceite em: $01 / 10 / 2021$ 
Assim, é necessário compreendermos os conceitos de prática e de teoria para superar a fragmentação entre elas. Pimenta e Lima chamam a atenção para o reducionismo dos estágios voltados à prática: “[...] A dissociação entre teoria e prática aí presente resulta em um empobrecimento das práticas nas escolas, o que evidencia a necessidade de explicar por que o estágio é teoria $e$ prática (e não teoria ou prática)." (PIMENTA; LIMA, 2011, p. 41). De acordo com as autoras, devem-se evitar posturas dicotômicas, em que teoria e prática sejam tratadas isoladamente durante o estágio supervisionado, pois a teoria e a prática se constituem, baseando-se em ação-reflexãoação da práxis.

Ainda se percebe que a articulação entre teoria e prática é um desafio, requer uma reflexão contínua do fazer pedagógico, pois

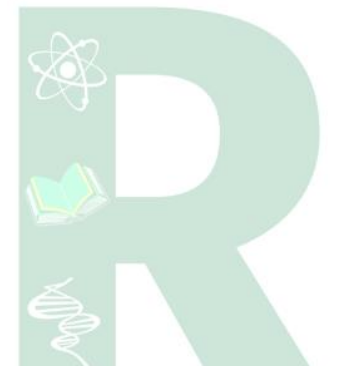

Tornar o estágio esse espaço de aprendizagem que leva a refazer continuamente a prática e a descobrir novos jeitos de conviver e compreender o fazer pedagógico é o desafio enfrentado nos diversos cursos de formação por alunos e professores na superação entre o abismo que se criou entre teoria e prática (GHEDIN, OLIVEIRA E ALMEIDA, 2015, p.194).

A articulação entre teoria e prática nos cursos de formação de professores é uma necessidade, pois, além de ser uma exigência da Resolução CNE/CP n. 2/2019 e Resolução CNE/CP n. 2/2015, contribuiu para a formação de sujeitos autônomos, que investigam suas práticas continuamente, permitindo a reflexão e a intervenção das práticas educativas. Os autores citados defendem uma concepção de estágio como momento de articulação entre teoria e prática e como um espaço para reflexão, pesquisa e transformação da realidade.

\subsection{Estágios como espaço para construção de saberes e da identidade docente}

Os trabalhos desta categoria discutem o estágio como espaço para construção de saberes e da identidade docente seja de professores supervisores (saberes sobre o ensinar a ensinar) ou dos licenciandos. As palavras chaves utilizadas para classificar essa categoria foram: saberes, saberes docentes, identidades docentes, características identitárias iniciais. Os autores discutem os saberes docentes mobilizados durante a

Recebido em: 10/01/2021

Aceite em: 01/10/2021 
supervisão dos estágios supervisionados, mostrando que os saberes advêm de conhecimentos teóricos, vivenciais, pedagógicos e disciplinares. Como exemplo, apresentamos o seguinte trabalho:

[...] analisar os dizeres de um grupo de formadores de professores de química, da educação básica, sobre os conhecimentos e ações formativas envolvidas nos estágios curriculares, buscando indícios que configurem seus saberes sobre o ensinar a ensinar (SID01, p.1).

A obtenção de saberes docentes é uma temática bastante discutida na formação de professores, pois estes são saberes necessários às práticas pedagógicas dos professores. (TARDIF, 1991; GAUTHIER, 1998, SHULMAN, 1986). Os trabalhos analisados apresentam os saberes docentes em uma perspectiva conceitual e tipológica, trazendo semelhanças e diferença, procurando mostrar a importância dos mesmos para a formação, atuação e desenvolvimento dos professores.

Quanto à identidade docente, são apontadas as características identitárias iniciais dos licenciandos a partir dos estágios, trazendo indicadores que caracterizem os saberes que um professor deveria possuir. Por exemplo, o trabalho SID04 objetivou

evidenciar, por meio de um questionário, características identitárias iniciais dos licenciandos a partir de seu primeiro contato com o ambiente escolar mediante uma disciplina de estágio de observação (SID04, p.1).

Esse estudo discute o processo de construção da identidade docente, ratificando que essa construção é um processo longo e de muitas inquietações. Desse modo, percebemos que os saberes e a identidade do professor são construídos ao longo de sua trajetória como profissional, “[...] Sendo o estágio, por excelência, um lugar de reflexão sobre a construção e o fortalecimento da identidade" (PIMENTA; LIMA, 2011, p.62). A identidade é construída ao longo da vida e, certamente, a identidade profissional ao longo da trajetória profissional.

Buriolla (2011, p. 15) afirma que o estágio "é o lócus onde a identidade profissional é gerada, construída e referida; volta-se para o desenvolvimento de uma ação vivenciada, reflexiva e crítica e, por isso, deve ser planejado gradativa e sistematicamente com essa finalidade". É dessa forma que a identidade vai se 
construindo, a partir da história individual e coletiva do sujeito. Histórias de vida que revelam experiências sociais. Com isso, o curso de licenciatura, o estágio, as demais disciplinas e as experiências vivenciadas na universidade e fora dela ajudam a construir a identidade docente.

Dessa forma, "o estágio, ao promover a presença do aluno estagiário no cotidiano da escola, abre espaço para a realidade e para a vida e o trabalho do professor na sociedade" (PIMENTA; LIMA 2011, p. 67, 68). Assim, o estágio supervisionado é como uma iniciação profissional, ou seja, uma iniciação à docência, de muita importância. A vivência do estágio é única e intransferível. É nesse processo que o estudante tem acesso a vários conhecimentos e saberes que o qualificará a ingressar na carreira docente.

\subsection{Estágios como espaço para pesquisa}

Nesta categoria, agrupou-se a maior quantidade de trabalhos, um total de 16 trabalhos. Estes apresentam o Estágio Supervisionado como espaço para a pesquisa, concepção defendida por autores com Pimenta e Lima (2011) e Ghedin, Oliveira e Almeida (2015). Desse modo, "a pesquisa no estágio é uma estratégia, um método, uma possibilidade de formação do estagiário como futuro professor" (PIMENTA; LIMA 2011, p.46), possibilitando a ampliação e estudo dos contextos em que os estágios se realizam.

Assim, as pesquisas englobadas nessa categoria vêm apresentando a utilização de alguns métodos ou estratégias de ensino empregados durante a etapa do estágio supervisionado, que foram posteriormente selecionados, organizados, comparados e analisados à luz do rigor científico, desenvolvendo no licenciando habilidades e postura que são exigidas por um pesquisador. As pesquisas aqui categorizadas visavam não apenas à aprendizagem do aluno da Educação Básica, mas também trazer reflexões em torno do impacto que tais estratégias didáticas têm na formação docente e na melhoria do ensino.

Os métodos ou estratégias de ensino utilizados como núcleo dessa categoria foram assim elencados: colaboração e comunicação docente; codocência expandida; 
investigação temática freiriana; realização de atividades de leitura e escrita na formação de professores; estudos da Diversidade Cultural; análises da prática docente inspirada na Intervenção Formativa (IF); Realização de Atividades na Perspectiva CTS; Comunidade de Práticas Científicas; construção de propostas didáticas e Perfis de desempenho.

Acreditamos que o Estágio como espaço para estratégias didáticas deve ser valorizado, pois esse é um espaço privilegiado de reflexão sobre as práticas pedagógicas, momento de ressignificação formativa em que o licenciando articula a melhor estratégia didática a ser aplicada, para que o aluno alcance o conhecimento. Assim, o Estágio Supervisionado precisa tornar-se um espaço de pesquisas e de investigação das práticas pedagógicas, para que o professor se torne um professor pesquisador de sua prática (PIMENTA; LIMA, 2011).

O estágio como espaço para pesquisas implica a proposição de pesquisas a serem desenvolvidas nessa etapa, para o entendimento das situações vivenciadas pelo professor, ou ainda, ou logo após, para ampliação e análises dos contextos em que eles se realizaram (PIMENTA; LIMA, 2011). Há também a possibilidade de o licenciando desenvolver habilidades de pesquisador a partir da elaboração de propostas ou projetos que lhes permitam uma compreensão e problematização de situações que vivenciam o espaço escolar e de buscar novo conhecimento a partir das explicações existentes, articulando com os novos dados que a realidade educacional impôs, e que são compreendidas por meio da postura investigativa.

Podemos citar como exemplo o trabalho P10 sobre a docência por investigação durante as atividades de estágio,

\footnotetext{
Dessa forma, nosso objetivo é verificar a mudança na qualidade do trabalho docente com a nova proposição, por meio da seguinte questão: que tipo de mudança/reflexão encontramos nos relatórios de estágio de docência nesse novo processo formativo embasado em referenciais de formação de professores? (P10, p.2).
}

Esse estudo traz uma aproximação entre pesquisa e prática docente, demonstrando que a docência por investigação pode trazer resultados positivos para a prática docente. No mapeamento realizado por Assai, Broietti e Arruda (2018) em periódicos da área de 
Ensino de Ciências, aponta-se um número expressivo de artigos que apresentam propostas e estratégias de ensino como parte do estágio:

[...] Encontramos uma variedade de propostas desenvolvidas pelos licenciandos ao longo do estágio supervisionado, tais como: utilização de metáforas; ações interdisciplinares; abordagens incluindo a História e Filosofia da Ciência; Ciclo da Experiência Kellyana (CEK) atrelado ao método da aprendizagem cooperativa; uso de textos de divulgação científica; [...] (ASSAI; BROIETTI; ARRUDA p.12, 2018).

Nessa perspectiva, diferentes métodos ou estratégias didáticas podem ser aplicados durante os Estágios Supervisionados com o intuito de tornar a formação de professores um ambiente propício para utilização de pesquisas, contribuindo para a formação de um profissional crítico, reflexivo e pesquisador.

4.4 Estágios nas concepções de professores formadores, supervisores, pósgraduandos e licenciandos

O Estágio nos cursos licenciatura tem sido objeto de várias pesquisas, entretanto, ainda são limitados os estudos que buscam investigar os sujeitos envolvidos na tríade formativa (ASSAI; BROIETTI; ARRUDA, 2018; LÓPEZ; NARDI, 2017). Encontramos nesta categoria o estágio na perspectiva de três sujeitos: professores formadores, professores supervisores, pós-graduandos/Licenciandos. As palavras chaves utilizadas para classificar a categoria foram: licenciandos, supervisor, professor e pós-graduando.

Os trabalhos, em maior número, abordam as concepções dos licenciandos, buscando compreender os alunos, seus anseios e conceitos sobre interdisciplinaridade durante o estágio. Como exemplo, a pesquisa PFSPGL02 vem relatando os objetivos e expectativas dos licenciandos sobre o estágio supervisionado, mostrando a importância da disciplina para uma maior aproximação com a realidade profissional.

[...] Objetivando analisar anseios e concepções sobre o estágio, esta pesquisa investigou a compreensão, expectativa e anseios didáticos pedagógicos de

Recebido em: 10/01/2021

Aceite em: $01 / 10 / 2021$ 
alunos do $4^{\circ}$ período do curso de Licenciatura em Ciências Biológicas da UFMS sobre o estágio [...] (PFSPGL02, p.1).

O mapeamento realizado por López e Nardi (2017) traz um panorama geral do que vem sendo publicado em eventos nacionais na área de Física sobre estágio supervisionado, apresentando a categoria "sujeitos implicados no estágio" e ratifica que o estagiário é o objeto de estudo mais investigado.

Sabendo da importância dos professores supervisores do estágio, os trabalhos encontrados versaram sobre alguns aspectos de Desenvolvimento Profissional Docente da supervisão dos estagiários das licenciaturas. Como exemplo dos trabalhos encontrados, a pesquisa PFSPGL04 trata o desenvolvimento profissional docente na supervisão dos estagiários e seus autores apontam para a necessidade de uma maior aproximação entre a universidade e os professores supervisores de estágio.

Estudou-se o desenvolvimento profissional docente de professores de Ciências e Biologia na supervisão dos estagiários das licenciaturas (PFSPGL04, p.1)

Endossando a ideia anterior, é necessário investir em pesquisas que retratem a tríade formativa, em especial a do professor supervisor, pois, muitas vezes, ele é considerado um mero carimbador de fichas e documentos para constar nos registros dos licenciandos, sem refletir com os mesmos sobre a prática vivenciada (ASSAI; BROIETTI; ARRUDA, 2018).

Quanto aos professores formadores, as pesquisas estão voltadas para entender como ocorre a prática docente de formadores durante o estágio, de modo a contribuir para uma melhor formação do licenciando. Daí a importância desse tipo de estudos, pois os professores supervisores e formadores do estágio contribuem significativamente para a formação docente (LÓPEZ; NARDI, 2017).

Segundo Pimenta e Lima (2011, p. 156), “estudar a sala de aula como espaço de conhecimento compartilhado vem se tornando uma necessidade pedagógica indispensável para a compreensão dos processos de ensinar e aprender" devido à importância da tríade formativa (professor formador/supervisor de estágio/licenciando) e do conhecimento compartilhado durante os processos de formação de professores.

Recebido em: 10/01/2021

Aceite em: $01 / 10 / 2021$ 


\subsection{Estágios em espaços não formais}

Como discutido anteriormente, um dos desafios da contemporaneidade é a melhoria da formação inicial de professores (SOUSA; SILVA; BEDIN, 2020). Assim a utilização de espaços não formais, como praças, teatros, parques, museus, empresas, estudos do meio entre outros (CARVALHO, 2012) pode promover aulas diferenciadas e ampliar os contextos de formação.

Os trabalhos agrupados nessa categoria estão voltados para discutir a influência do estágio em espaços de educação não formal, e as palavras chaves utilizados foram: Centro de Ciências e Planetário do Pará, instituições museológicas. Como exemplo, a pesquisa ENF01 vem apresentando o museu como possibilidade de estágio não formal, trazendo uma discussão sobre a possibilidade de ampliação dos espaços de atuação do profissional de educação em Ciências.

Neste estudo, problematizamos os múltiplos sentidos da produção discursiva dos estagiários do curso de ciências biológicas no acesso às instituições museológicas (ENF01, p.1).

Como mencionado, existem inúmeros espaços não formais que podem ser utilizados para o ensino e aprendizagem de Ciências, assim como de formação de professores. Quanto ao espaço do museu, Carvalho (2012, p.97) aponta que "[...] Em paralelo a esse trabalho feito pelos museus, as escolas têm buscado nessas instituições uma complementaridade ao ensino desenvolvido dentro das salas de aula, influenciadas pelas propostas curriculares atuais. [...]”. Assim, esses espaços não formais podem ser uma complementaridade ao ensino desenvolvido dentro das salas de aula, e os estágios supervisionados podem ser um importante ambiente de ensino.

Cabe salientar que para que os estágios supervisionados ocorram em ambientes não formais, é necessário que os professores estabeleçam parcerias com os espaços pretendidos, além de conhecer a linguagem e as práticas específicas do local, relacionado-as com os objetivos educacionais pretendidos. Assim, pesquisas sobre o ensino em espaços não formais devem ser realizadas como propostas de melhorais para a educação.

Recebido em: 10/01/2021

Aceite em: $01 / 10 / 2021$ 


\section{CONSIDERAÇÕES FINAIS}

O estudo permitiu conhecer o que as mais recentes edições do ENPEC vêm publicando sobre estágio supervisionado. Percebeu-se grande número de produções na área a partir da publicação da Resolução CNE/CP 02/2015, de 01 de julho de 2015 (BRASIL, 2015), que definiu as Diretrizes Curriculares Nacionais para a formação inicial em nível superior e a carga horária mínima para os estágios supervisionados, apontando a preocupação dos cursos de formação de professores em discutir e acatar a referida Resolução.

Percebe-se que na área de Química os trabalhos estão voltados para pesquisas sobre teoria e prática na ação docente, saberes e identidade docente e estágio com pesquisas: colaboração docente, atividades de leitura e escrita e perspectiva CTS. Também é foco de estudo a visão dos pós-graduandos sobre estágio supervisionado. Já na área de Física, os trabalhos versam sobre prática como componente curricular, saberes docentes, situações de codocência, docência por investigação e propostas didáticas, além de estudos sobre o professor supervisor dos estágios e estágio em espaços não formais. Quanto à área da Biologia, as pesquisas centram-se em todas as categorias, com produções sobre os saberes e identidade docente, e estágio com pesquisa: investigação temática freiriana, perspectiva CTS, diversidade cultural, estágio na concepção dos licenciandos e supervisores de estágio, além de espaços não formais, como museus.

As publicações do evento do Ensino de Ciências aqui analisadas, o ENPEC, não diferem do que os outros eventos ou periódicos da área vêm discutindo, conforme o mapeamento realizado nas pesquisas de Assai, Broietti e Arruda (2018), que apresenta as categorias: legislação e currículo; instrumentos formativos; ação docente; concepções dos estagiários; aprendizagem docente; identidade docente e tríade formativa. Já López e Nardi (2017), apresentam categorias: sujeitos implicados no ESC; estágio e pesquisa e processo do ECS.

Outras pesquisas que abordem a temática sobre Estágios supervisionados devem ser realizadas, principalmente sobre as contribuições do mesmo para a formação continuada de professores supervisores, visto que encontramos poucas discussões nessa

Recebido em: 10/01/2021

Aceite em: $01 / 10 / 2021$ 
área, ficando como desafios para futuras pesquisas. A supervisão de estagiários das licenciaturas é uma excelente oportunidade de formação continuada de professores porque significa uma possibilidade de desenvolvimento profissional docente frente aos profissionais em exercício.

As informações aqui apresentadas contribuem para repensar a formação de professores do ensino de Ciências e as práticas formativas vivenciadas por estagiários, professores formadores e professores supervisores durante os estágios supervisionados.

Nesse contexto de formar professores para o ensino de Ciências pesquisadores de sua prática, existem perguntas que ainda precisam ser respondidas, tais como: nos cursos de Licenciatura, como introduzir o estágio logo nos primeiros anos da formação? Ou, como introduzir o estágio com pesquisa? O Estágio Supervisionando deve ser valorizado como potencializador da formação de um profissional crítico, reflexivo e pesquisador da ação docente.

\section{REFERÊNCIAS}

ASSAI, Natany, Dayani de Souza; BROIETTI, Fabiele Cristiane Dias; ARRUDA, Sergio de Mello. O Estágio Supervisionado na Formação Inicial de Professores: Estado da Arte das Pesquisas Nacionais da Área de Ensino de Ciências. Educação em Revista, Belo Horizonte, v.34 e 203517, 2018.

BARDIN, Laurence. Análise de conteúdo. São Paulo: Edições 70, p. 229,2011.

BRASIL. LDB - Lei de Diretrizes e Bases da Educacional. Lei 9394/96. Brasília, DF, dez 1996.

Lei do Estágio de estudantes. Lei 11.788/2008. Brasília, DF, set 2018.

Conselho Nacional de Educação. Resolução CNE/CP 2/2002 de 19 de

fevereiro de 2002. Institui a duração e a carga horária dos cursos de licenciatura, de graduação plena, de formação de professores da Educação Básica em nível superior.

. Conselho Nacional de Educação. Resolução CNE/CP no 02/2015, de $1^{\circ}$ de

julho de 2015. Define as Diretrizes Curriculares Nacionais para a formação inicial em nível superior (cursos de licenciatura, cursos de formação pedagógica para graduados e cursos de segunda licenciatura) e para a formação continuada. Brasília, Diário Oficial [da] República Federativa do Brasil, seção 1, n. 124, p. 8-12, 02 de julho de 2015.

Recebido em: 10/01/2021

Aceite em: 01 / 10/2021 
Conselho Nacional de Educação. Resolução n. 2/2019, de 20 de dezembro

de 2019. Define as Diretrizes Curriculares Nacionais para a Formação Inicial de Professores para a Educação Básica e institui a Base Nacional Comum para a Formação Inicial de Professores da Educação Básica (BNC-Formação). Diário Oficial [da] República Federativa do Brasil, seção 1, n. 28, p. 115-119, 10 de fev. de 2020.

BURIOLLA, Marta. Alice Feiten. O estágio supervisionado. 7 ed. São Paulo: Cortez, 2011.

CARVALHO, Anna Maria Pessoa. Os estágios nos Cursos de Licenciaturas. São Paulo: Cengage Learning, 2012.

DINIZ-PEREIRA, Julio. Emilio. Da racionalidade técnica a racionalidade crítica: formação docente e transformação social. Perspectivas em Diálogo: Revista de Educação e Sociedade, v. 01, n. 01, p.34-42, 2014.

GAUTHIER, Clermont, et al. Por uma teoria da pedagogia: pesquisas contemporâneas sobre o saber docente. Ijuí: Ed. Unijuí, (Coleção Fronteiras da Educação). 1998.

GHEDIN, Evandro; OLIVEIRA, Elisângela S de; ALMEIDA, Whasgthon A. de. Estágio com Pesquisa. São Paulo: Cortez, 2015.

GÜNZEL, Rafaela Engers Günzel. Ensinar é aprender: desafios e experiências no estágio de Docência. Revista Insignare Scientia - RIS, v. 2, n. 3, p. 222-232, 21 nov. 2019.

HORIKAWA, Alice Yoko. A formação de professores: perspectiva histórica e concepções. Formação Docente, Belo Horizonte, v. 07, n. 13, p. 11-30, ago./dez. 2015.

JANERINE, Aline de Souza; QUADROS, Ana Luiza de. A formação de professores: analisando uma experiência formativa. Revista Insignare Scientia - RIS, v. 1, n. 1, 18 jun. 2018.

LINHEIRA, Caroline Zabendzala; NETO, José Xavier Costa; JÓFILI, Zélia Maria Soares. A percepção de estudantes sobre sua participação no estágio supervisionado em ciências: análise da prática educativa. XII Encontro Nacional de Pesquisa em

Educação em Ciências - XII ENPEC. Universidade Federal do Rio Grande do Norte, Natal, RN - 25 a 28 de junho de 2019.

LÓPEZ, Tatiana Iveth Salazar; NARDI, Roberto. Um panorama da pesquisa sobre o estágio curricular supervisionado relatada em eventos acadêmicos nacionais. XI

Encontro Nacional de Pesquisa em Educação em Ciências - XI ENPEC.

Universidade Federal de Santa Catarina, Florianópolis, SC - 3 a 6 de julho de 2017.

NÓVOA, Antonio. Firmar a Posição Como Professor, Afirmar a Profissão Docente.

Cadernos de Pesquisa v.47 n.166 p.1106-1133 out./dez. 2017.

Recebido em: 10/01/2021

Aceite em: $01 / 10 / 2021$ 
PIMENTA, Selma Garrido; LIMA, Maria Socorro Lucena. Estágio e docência. 8. ed. São Paulo:Cortez, 2011.

SOUZA, Denise Santos de; SILVA, Cristiane Santos de Souza da; BEDIN, Everton. A relevância da observação na formação inicial docente com vistas no desenvolvimento da prática reflexiva. Revista Insignare Scientia - RIS, v. 3, n. 1, p. 322-339, 4 jun. 2020.

SHULMAN, Lee. Those who understand: Knowledge growth in teaching. Educational Researcher 15(2), p. 4-14, 1986.

TARDIF, Maurice et al. Os Professores Face ao Saber: esboço de uma problemática do saber docente. Teoria \& Educação, Porto Alegre, n. ${ }^{\circ}$ 4, p.215-233, 1991.

VEIGA, Ilma Passos Alencastro; VIANA, Cleide Maria Quevedo Quixadá. Formação de professores: um campo de possibilidades inovadoras. In: VEIGA, I. P. A.; SILVA, E. F. (orgs.) A escola mudou. Que mude a formação de professores! 3ed. Campinas, SP: Papirus, p.13-34, 2012.

Recebido em: 10/01/2021

Aceite em: 01 / 10/2021 


\section{ANEXOS}

Quadro 2 - Trabalhos analisados.

\begin{tabular}{|c|c|c|c|c|c|}
\hline \multicolumn{6}{|c|}{ 1-ESTÁGIO: TEORIA E PRÁTICA NA AÇÃO DOCENTE } \\
\hline $\mathbf{N}^{\mathbf{o}}$ & Título e Autor & Evento & Área & $\begin{array}{l}\text { Palavra } \\
\text { Chave }\end{array}$ & Código \\
\hline 1 & $\begin{array}{l}\text { O Estágio Supervisionado e a Prática } \\
\text { como Componente Curricular na matriz } \\
\text { do curso de Licenciatura em Química da } \\
\text { UFGD. Adriana Marques de Oliveira; } \\
\text { Maria Amelia Monteiro }\end{array}$ & $\begin{array}{l}\text { ENPEC } \\
2019\end{array}$ & Química & $\begin{array}{l}\text { relação teórico- } \\
\text { prática }\end{array}$ & ТР01 \\
\hline 2 & $\begin{array}{l}\text { O Aporte Teórico-Prático no } \text { Estágio } \\
\text { Supervisionado Investigativo: } \\
\text { Entre Texaçãão } \\
\text { De Investigação. Alexander o Problema } \\
\text { Cunha }\end{array}$ & $\begin{array}{l}\text { ENPEC } \\
2019\end{array}$ & Física & $\begin{array}{l}\text { prática Como } \\
\text { Componente } \\
\text { Curricular }\end{array}$ & ТР02 \\
\hline 3 & $\begin{array}{l}\text { Teoria e Prática na Ação Docente: } \\
\text { Compreensões de Professores em } \\
\text { Formação. Vivian dos Santos Calixto; } \\
\text { Neide Maria Michellan Kiouranis; Rui } \\
\text { Marques Vieira }\end{array}$ & $\begin{array}{l}\text { ENPEC } \\
2019\end{array}$ & Química & teórico-prática & ТР03 \\
\hline \multicolumn{6}{|c|}{ 2-CONSTRUÇÃO DE SABERES E DA IDENTIDADE DOCENTE } \\
\hline $\mathbf{N}^{\mathbf{o}}$ & Título e Autor & Evento & Área & $\begin{array}{l}\text { Palavra } \\
\text { Chave }\end{array}$ & Código \\
\hline 4 & $\begin{array}{l}\text { Saberes Docentes Mobilizados no Estágio } \\
\text { Supervisionado em Química. Lidiane } \\
\text { Borges Dutra Muniz; José Gonçalves } \\
\text { Teixeira Júnior; Rejane Maria Ghisolfi } \\
\text { Silva }\end{array}$ & $\begin{array}{l}\text { ENPEC } \\
2017\end{array}$ & Química & saberes & SID01 \\
\hline 5 & $\begin{array}{l}\text { Por Entre Diálogos: Significados e } \\
\text { Sentidos Sobre o Estágio Supervisionado } \\
\text { no Curso de Licenciatura em Ciências } \\
\text { Biológicas. Aline Neves Vieira De } \\
\text { Santana; José Firmino de Oliveira } \\
\text { Neto; Marilda Shuvartz Signin }\end{array}$ & $\begin{array}{l}\text { ENPEC } \\
2017\end{array}$ & $\begin{array}{l}\text { Ciências } \\
\text { Biológicas }\end{array}$ & $\begin{array}{l}\text { identidades } \\
\text { docente }\end{array}$ & SID02 \\
\hline 6 & $\begin{array}{l}\text { Parceria Universidade-Escola no Estágio } \\
\text { Supervisionado: a Construção de Saberes }\end{array}$ & $\begin{array}{c}\text { ENPEC } \\
2019\end{array}$ & $\begin{array}{l}\text { Ciências } \\
\text { Biológicas }\end{array}$ & saberes docentes & SID03 \\
\hline
\end{tabular}

Recebido em: 10/01/2021

Aceite em: 01/10/2021 


\begin{tabular}{|c|c|c|c|c|c|}
\hline & 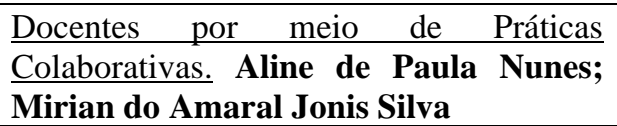 & & & & \\
\hline 7 & $\begin{array}{l}\text { Análise Da Construção Da Identidade } \\
\text { Docente Em Um Estágio De Observação. } \\
\text { Cássia Emi Obara; Fabiele Cristiane } \\
\text { Dias Broietti ; Natany Dayani De Souza } \\
\text { Assai ; Viviane } \quad \text { Arrigo; Marinez } \\
\text { Meneghello Passos }\end{array}$ & $\begin{array}{l}\text { ENPEC } \\
2019\end{array}$ & Química & $\begin{array}{l}\text { características } \\
\text { identitárias } \\
\text { iniciais }\end{array}$ & SID04 \\
\hline 8 & $\begin{array}{l}\text { Discursos de Futuros } \text { Professores } \\
\text { Cursando o último ano de Licenciatura } \\
\text { sobre os Saberes essenciais que deve ter } \\
\text { um Professor. Tatiana Iveth Salazar } \\
\text { López ; Roberto Nardi }\end{array}$ & $\begin{array}{l}\text { ENPEC } \\
2019\end{array}$ & Física & saberes docentes & SID05 \\
\hline & \multicolumn{5}{|c|}{ 3-ESTÁGIO COMO ESPAÇO PARA PESQUISAS. } \\
\hline $\mathbf{N}^{\mathbf{o}}$ & Título e Autor & Evento & Área & $\begin{array}{l}\text { Palavra } \\
\text { Chave }\end{array}$ & Código \\
\hline 9 & $\begin{array}{l}\text { Estágio Supervisionado e Colaboração } \\
\text { Docente: Dois Caminhos Que Se Cruzam. } \\
\text { Corrêam Marcos; Martins, Isabel }\end{array}$ & $\begin{array}{c}\text { ENPEC } \\
2017\end{array}$ & & $\begin{array}{l}\text { colaboração } \\
\text { docente }\end{array}$ & P01 \\
\hline 10 & $\begin{array}{l}\text { Um Panorama da Pesquisa Sobre o } \\
\begin{array}{lll}\text { Estágio } & \text { Curricular } & \text { Supervisionado } \\
\text { Relatada } & \text { em } & \text { Eventos } \quad \text { Acadêmicos } \\
\text { Nacionais. } & \text { Tatiana } & \text { Salazar, Roberto }\end{array} \\
\text { Nardi }\end{array}$ & $\begin{array}{l}\text { ENPEC } \\
2017\end{array}$ & Física & $\begin{array}{l}\text { Estágio } \\
\text { Curricular } \\
\text { supervisionado }\end{array}$ & $\mathrm{P} 02$ \\
\hline 11 & $\begin{array}{l}\text { Espaço Comunicativos em Estágio } \\
\text { Curricular de Licenciatura em Química: } \\
\text { Análise De Documentos Institucionais. } \\
\text { Andréia Florêncio Eduardo de Deus; } \\
\text { Noemi Sutil }\end{array}$ & $\begin{array}{l}\text { ENPEC } \\
2017\end{array}$ & Química & $\begin{array}{l}\text { Espaços } \\
\text { comunicativos }\end{array}$ & $\mathrm{P} 03$ \\
\hline 12 & $\begin{array}{l}\text { Estágio Supervisionado em Biologia: } \\
\begin{array}{ll}\text { Articulando Formação de } \\
\text { Investigação }\end{array} \text { Temática } \\
\text { Oda }\end{array}$ & $\begin{array}{l}\text { ENPEC } \\
2017\end{array}$ & Biologia & $\begin{array}{l}\text { Investigação } \\
\text { Temática } \\
\text { Freiriana }\end{array}$ & P04 \\
\hline 13 & $\begin{array}{l}\text { Movimentos de Leitura e Escrita na } \\
\text { Disciplina de Estágio Supervisionado em } \\
\text { Química em uma Universidade Pública de } \\
\text { MG. Wallace Cabral, Cristhiane Flôr }\end{array}$ & $\begin{array}{l}\text { ENPEC } \\
2017\end{array}$ & Química & $\begin{array}{l}\text { atividades de } \\
\text { leitura e escrita }\end{array}$ & P05 \\
\hline 14 & $\begin{array}{l}\text { A Codocência Expandida no Contexto do } \\
\text { Estágio Supervisionado em Física. Célio } \\
\text { Da Paz Farroco; Pedro Henrique } \\
\text { Forgane Franco; Cristiano Rodrigues } \\
\text { De Mattos; Glauco Dos Santos Ferreira } \\
\text { Da Silva }\end{array}$ & $\begin{array}{l}\text { Enpec } \\
2019\end{array}$ & Física & $\begin{array}{ll}\text { situações } & \text { de } \\
\text { codocência } & \end{array}$ & P06 \\
\hline 15 & $\begin{array}{l}\text { A Codocência no Contexto do Estágio } \\
\begin{array}{l}\text { Supervisionado: } \\
\text { Uma Proposta de }\end{array} \\
\text { Análise. Pedro Henrique Forgane } \\
\text { Franco; Célio Da Paz Farroco; Glauco } \\
\text { Dos Santos Ferreira Da Silva; Celso }\end{array}$ & $\begin{array}{l}\text { ENPEC } \\
2019\end{array}$ & Física & $\begin{array}{l}\text { codocência } \\
\text { expandida }\end{array}$ & P07 \\
\hline
\end{tabular}

Recebido em: 10/01/2021

Aceite em: 01/10/2021 


\begin{tabular}{|c|c|c|c|c|c|}
\hline & Suckow Da Fonse & & & & \\
\hline 16 & $\begin{array}{l}\text { Estágio Supervisionado em Ensino de } \\
\text { Química: Analisando a Prática Docente a } \\
\text { Partir da Abordagem Comunicativa e dos } \\
\text { Enfoques para o Ensino de Ciências na } \\
\text { Sala de Aula. Leiliane Alves } \\
\text { Silva; Bruna Herculano Da Silva } \\
\text { Bezerra; Flávia Cristiane Vieira Da } \\
\text { Silva }\end{array}$ & $\begin{array}{l}\text { ENPEC } \\
2019\end{array}$ & Química & $\begin{array}{l}\text { abordagem } \\
\text { comunicativa do } \\
\text { professor }\end{array}$ & P08 \\
\hline 17 & $\begin{array}{l}\text { Os Desafios do Estágio Supervisionado e } \\
\text { a Formação do Professor Sensível à } \\
\text { Diversidade Cultural. Aluska da Silva } \\
\text { Matias; Geilsa Costa Santos Baptista }\end{array}$ & $\begin{array}{l}\text { ENPEC } \\
2019\end{array}$ & $\begin{array}{l}\text { Ciências } \\
\text { Biológicas }\end{array}$ & $\begin{array}{l}\text { diversidade } \\
\text { cultural }\end{array}$ & P09 \\
\hline 18 & $\begin{array}{l}\text { Docência por } \\
\text { Experiência } \\
\text { Envestigação: }\end{array}$ & $\begin{array}{l}\text { ENPEC } \\
2019\end{array}$ & Física & $\begin{array}{ll}\text { relatórios } & \text { de } \\
\text { estágio } & \end{array}$ & P10 \\
\hline 19 & 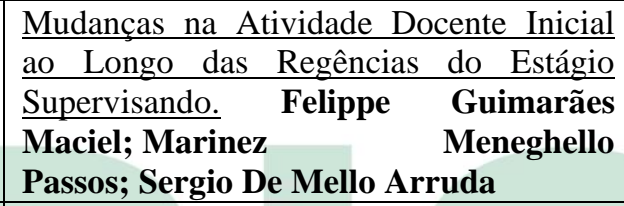 & $\begin{array}{l}\text { ENPEC } \\
2019\end{array}$ & Física & $\begin{array}{l}\text { intervenção } \\
\text { formativa (IF) }\end{array}$ & P11 \\
\hline 20 & $\begin{array}{l}\text { O Estágio Supervisionado da Licenciatura } \\
\text { em Química: Reflexões entre o Planejado } \\
\text { e o Realizado. Graziela Piccoli } \\
\text { Richetti; Marcelo Lambach }\end{array}$ & $\begin{array}{l}\text { ENPEC } \\
2019\end{array}$ & Química & perspectiva CTS & P12 \\
\hline 21 & $\begin{array}{l}\text { O Estágio Em Ensino de Ciências Como } \\
\text { Possibilidade de Envolvimento em } \\
\text { Comunidade de Práticas Científicas. } \\
\text { Raquel Sousa Valois; Lúcia Helena } \\
\text { Sasseron }\end{array}$ & $\begin{array}{c}\text { ENPEC } \\
2019\end{array}$ & Pedagogia & $\begin{array}{l}\text { comunidade de } \\
\text { práticas } \\
\text { científicas }\end{array}$ & P13 \\
\hline 22 & $\begin{array}{l}\text { A Temática Étnico-Racial na Formação } \\
\text { Inicial de Professores de Ciências } \\
\text { Biológicas. Maria da Conceição Costa } \\
\text { Melo; Suzane Bezerra França }\end{array}$ & $\begin{array}{l}\text { ENPEC } \\
2019\end{array}$ & $\begin{array}{l}\text { Ciências } \\
\text { Biológicas }\end{array}$ & $\begin{array}{l}\text { abordagem da } \\
\text { temática étnico- } \\
\text { racial }\end{array}$ & P14 \\
\hline 23 & $\begin{array}{l}\text { História e Filosofia da Ciência na } \\
\text { Formação de Professores de Física: } \\
\text { Potencialidades e Limites da Construção } \\
\text { de Propostas Didáticas. Sarah Orthmann } \\
\text { Tavernard de Alencar; André Ary } \\
\text { Leonel }\end{array}$ & $\begin{array}{l}\text { ENPEC } \\
2019\end{array}$ & Física & $\begin{array}{l}\text { propostas } \\
\text { didáticas } \\
\text { envolvendo } \\
\text { história e } \\
\text { filosofia da } \\
\text { ciência } \\
\end{array}$ & P15 \\
\hline 24 & 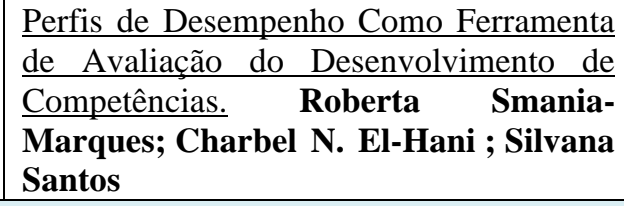 & $\begin{array}{c}\text { ENPEC } \\
2019\end{array}$ & $\begin{array}{l}\text { Ciências } \\
\text { Biológicas }\end{array}$ & taxonomia solo & P16 \\
\hline & $\begin{array}{l}\text { 4- ESTÁGIOS NAS CONCEP } \\
\text { SUPERVISORES, PÓS-GR }\end{array}$ & DUAND & S, E LICE & SCIANDOS. & RES, \\
\hline $\mathbf{N}^{\mathbf{o}}$ & Título e Autor & Evento & Área & Palavra & Código \\
\hline
\end{tabular}

Recebido em: 10/01/2021

Aceite em: 01/10/2021 


\begin{tabular}{|c|c|c|c|c|c|}
\hline & & & & Chave & \\
\hline 25 & $\begin{array}{l}\text { As Concepções de Interdisciplinaridade } \\
\text { dos Licenciandos em Ciências Naturais: o } \\
\text { Papel da Disciplina de Estágio } \\
\text { Supervisionado de Ensino. Nathália } \\
\text { Araújo, Delano Silva, Viviane Falcomer }\end{array}$ & $\begin{array}{c}\text { ENPEC } \\
2017\end{array}$ & $\begin{array}{l}\text { Ciências } \\
\text { Naturais }\end{array}$ & licenciandos & $\begin{array}{l}\text { PFSPG } \\
\text { L01 }\end{array}$ \\
\hline 26 & $\begin{array}{l}\text { Concepções e Expectativas Pedagógicas } \\
\text { de Graduandos do Curso de Licenciaturae } \\
\text { em Ciências Biológicas da Universidade } \\
\text { Federal de Mato Grosso do Sul Sobre o } \\
\text { Estágio Obrigatório. Clarisse Marques } \\
\text { de Almeida Dias; Ester Tartarotti }\end{array}$ & $\begin{array}{c}\text { ENPEC } \\
2017\end{array}$ & $\begin{array}{l}\text { Ciências } \\
\text { Biológicas }\end{array}$ & licenciandos & $\begin{array}{l}\text { PFSPG } \\
\text { L02 }\end{array}$ \\
\hline 27 & $\begin{array}{l}\text { Estágio de Docência: Espaço Formativo } \\
\text { do Docente do Ensino Superior na Área } \\
\text { de Ciências da Natureza. Hoffmann, } \\
\text { Marilisa Bialvo; Delizoicov, Demétrio }\end{array}$ & $\begin{array}{c}\text { ENPEC } \\
2017\end{array}$ & $\begin{array}{l}\text { Ciências } \\
\text { Naturais }\end{array}$ & pós-graduação & $\begin{array}{l}\text { PFSPG } \\
\text { L03 }\end{array}$ \\
\hline 28 & $\begin{array}{l}\text { A Supervisão de Estagiários da } \\
\text { Licenciatura como Possibilidade de } \\
\text { Desenvolvimento Profissional Docente } \\
\text { Para Professores De Ciências e Biologia. } \\
\text { Mello, Ana Cecília Romano De; Higa, } \\
\text { Ivanilda }\end{array}$ & $\begin{array}{c}\text { ENPEC } \\
2017\end{array}$ & $\begin{array}{l}\text { Ciências/ } \\
\text { Biologia }\end{array}$ & supervisão & $\begin{array}{l}\text { PFSPG } \\
\text { L04 }\end{array}$ \\
\hline 29 & $\begin{array}{l}\text { Inquietações Problematizadas Pelo } \\
\text { Exercício do Estágio Supervisionado em } \\
\text { Ciências. Bárbara G. Tobaldini De } \\
\text { Lima; Sandra Maria Wirzbicki }\end{array}$ & $\begin{array}{c}\text { ENPEC } \\
2017\end{array}$ & $\begin{array}{l}\text { Ciências } \\
\text { Biológicas }\end{array}$ & licenciandos & $\begin{array}{l}\text { PFSPG } \\
\text { L05 }\end{array}$ \\
\hline 30 & $\begin{array}{l}\text { O Professor de Estágio Supervisionado } \\
\text { Obrigatório na Produção Científica de } \\
\text { Eventos Nacionais. Edna Silva Barreto; } \\
\text { Monica Lopes Folena Araujo }\end{array}$ & $\begin{array}{c}\text { ENPEC } \\
2019 \\
\end{array}$ & & professor & $\begin{array}{l}\text { PFSPG } \\
\text { L06 }\end{array}$ \\
\hline 31 & $\begin{array}{l}\text { Caracterização da Prática Docente de } \\
\text { Uma Professora Supervisora de Estágio } \\
\text { Curricular de Ensino De Física. Marilene } \\
\text { Vieira; Fernanda Gall Centa; Eduardo } \\
\text { Adolfo Terrazzan }\end{array}$ & $\begin{array}{l}\text { ENPEC } \\
2019\end{array}$ & Física & supervisora & $\begin{array}{l}\text { PFSPG } \\
\text { L07 }\end{array}$ \\
\hline 32 & $\begin{array}{l}\text { A Concepção de um Grupo de Pós- } \\
\text { Graduandos e Professores sobre o Estágio } \\
\text { Docência e Seu Papel para a Formação } \\
\text { Docente. Victor Gomes Lima Ferraz; } \\
\text { José Guilherme Da Silva Lopes }\end{array}$ & $\begin{array}{c}\text { ENPEC } \\
2019\end{array}$ & Química & $\begin{array}{l}\text { pós-graduandos } \\
\text { e professores }\end{array}$ & $\begin{array}{l}\text { PFSPG } \\
\text { L08 }\end{array}$ \\
\hline 33 & 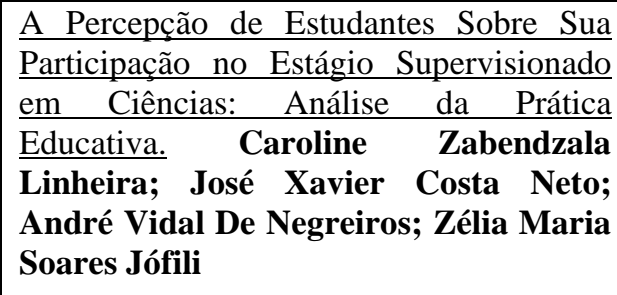 & $\begin{array}{c}\text { ENPEC } \\
2019\end{array}$ & $\begin{array}{l}\text { Ciências } \\
\text { Biológicas }\end{array}$ & estudantes & $\begin{array}{l}\text { PFSPG } \\
\text { L09 }\end{array}$ \\
\hline 34 & 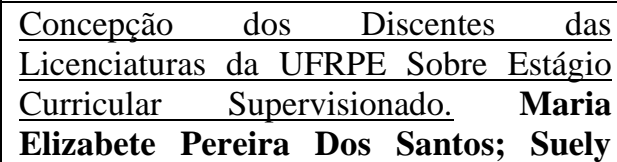 & $\begin{array}{c}\text { ENPEC } \\
2019\end{array}$ & $\begin{array}{l}\text { Ciências } \\
\text { da } \\
\text { Natureza/ } \\
\text { Matemátic }\end{array}$ & licenciandos & $\begin{array}{l}\text { PFSPG } \\
\text { L10 }\end{array}$ \\
\hline
\end{tabular}

Recebido em: 10/01/2021

Aceite em: 01/10/2021 


\begin{tabular}{|c|c|c|c|c|c|}
\hline & Alves Da Silva & & $\begin{array}{l}\text { a/ Ciências } \\
\text { agrícolas }\end{array}$ & & \\
\hline \multicolumn{6}{|c|}{ 5-ESTÁGIO EM ESPAÇOS NÃO FORMAIS } \\
\hline $\mathbf{N}^{\mathbf{0}}$ & Título e Autor & Evento & Área & $\begin{array}{l}\text { Palavra } \\
\text { Chave }\end{array}$ & Código \\
\hline 35 & $\begin{array}{l}\text { Estágio Supervisionado em } \text { Ciências } \\
\text { Biológicas nos Contextos não Escolares: } \\
\text { Reflexões e Subsídios para uma Agenda } \\
\text { Investigativa. Maria Cristina Ribeiro } \\
\text { Cohen }\end{array}$ & $\begin{array}{l}\text { ENPEC } \\
2017\end{array}$ & $\begin{array}{l}\text { Ciências } \\
\text { Biológicas }\end{array}$ & $\begin{array}{l}\text { instituições } \\
\text { museológicas }\end{array}$ & ENF01 \\
\hline 36 & 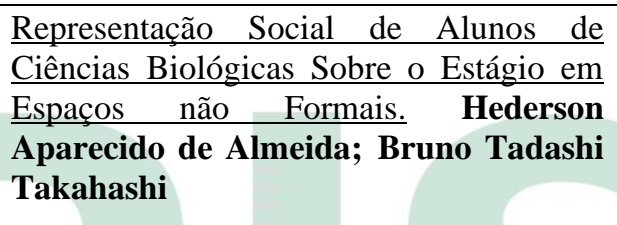 & $\begin{array}{l}\text { ENPEC } \\
2017\end{array}$ & $\begin{array}{l}\text { Ciências } \\
\text { Biológicas }\end{array}$ & $\begin{array}{l}\text { espaços não } \\
\text { formais }\end{array}$ & ENF02 \\
\hline 37 & $\begin{array}{l}\text { Formação Inicial e Subjetividade Docente } \\
\text { no Centro de Ciências e Planetário do } \\
\text { Pará. Victtor Takeshi Yano; José } \\
\text { Moyses Alves; André Luiz Rodrigues } \\
\text { dos Santos Cunha }\end{array}$ & $\begin{array}{l}\text { ENPEC } \\
2017\end{array}$ & Física & $\begin{array}{l}\text { Centro de } \\
\text { Ciências e } \\
\text { Planetário do } \\
\text { Pará (CCPP) }\end{array}$ & ENF03 \\
\hline
\end{tabular}

